\title{
FORMULAÇÃO DE ARGAMASSA EXPANSIVA PARA LAVRA DE ROCHAS ORNAMENTAIS UTILIZANDO MINÉRIOS NÃO-METÁLICOS DA REGIÃO NORDESTE DO PAÍS
}

\author{
Danielly Vieira de Lucena ' \\ Danyllo Vieira de Lucena ${ }^{2}$ \\ Carlos Magno Almeida Rocha Souto ${ }^{3}$
}

\begin{abstract}
Resumo
Sabendo-se que um dos métodos mais significativos de tecnologia avançada para lavra, no maciço rochoso, é o que emprega argamassa expansiva para corte de rocha e que toda a argamassa expansiva comercializada no mercado interno brasileiro é importada, assim como as que são industrializadas no país, possuem componentes provenientes do mercado externo, objetivo deste trabalho é desenvolver argamassas expansivas com matérias-primas regionais e que apresentem pressão de expansão suficiente para o desmonte de rochas do tipo granito e mármore. Para isto, são utilizadas formulações de argamassa expansiva utilizando óxido de cálcio, carbonato de cálcio, carboximetilcelulose - CMC, cimento (Portland), e a partir da análise química através de análise térmica, difração de raios-X e granulometria a laser compararam-se os resultados com de uma argamassa comercial. Os resultados indicaram que as formulações apresentaram características próximas ao da argamassa comercial.
\end{abstract}

Palavras-chave: Lavra de rochas; Argamassa expansiva; Caracterização.

\section{FORMULATION OF EXPANSIVE MORTAR TO TILL THE STONES USING NON-METALLIC MINERALS OF NORTHEAST OF COUNTRY}

\begin{abstract}
One of the most significant methods of advanced technology for mining, the rock massif is employing expansive mortar for cutting of Rock. Furthermore, the entire expansive mortar commercialized in the Brazilian domestic market are imported, as well as those in industrialized country. Both have components from the external market. The aim of this work is to develop expansive mortar with raw materials that have regional and pressure sufficient to remove the rocks of granite and marble type expansion. For this, expansive grout formulations using calcium oxide, calcium carbonate, carboxymethylcellulose are used - CMC (Portland) cement, and from the chemical analysis by means of thermal analysis, $X$-ray diffraction and laser granulometry compared the results with a commercial mortar. The results indicated that the formulations showed characteristics similar to the commercial mortar.
\end{abstract}

Keywords: Mining of rock; Expansive mortar; Characterization.

\section{INTRODUÇÃO}

A denominação de rochas ornamentais abrange uma grande variedade de materiais como mármores, travertinos, granitos, ardósias, quartzitos, serpentinitos, basaltos, pedrasabão e outros, utilizados principalmente na construção civil como material de acabamento e revestimento. Os materiais naturais de ornamentação e revestimento abrangem os tipos de rochas que podem ser extraídas em blocos ou placas, cortadas em formas variadas e posteriormente beneficiadas com polimentos, lustros etc. Do ponto de vista comercial, as rochas ornamentais e de revestimento são classificadas, principalmente, em mármores e granitos, que correspondem por cerca de $90 \%$ da produção mundial [I].

A indústria de rochas ornamentais tem grande relevância no mercado mundial, inclusive no Brasil, que é um dos grandes produtores e exportadores mundiais de rochas ornamentais e de revestimento [2].

Elas constituem um dos segmentos de maior crescimento no setor mineral brasileiro, com um incremento médio na pauta de exportação superior a $10 \%$ ao ano, proporcionado tanto por novos tipos de utilização destes

IInstituto Federal da Paraíba - IFPB, Campus Campina Grande, Campina Grande, PB, Brasil. E-mail: daniellymateriais@yahoo.com.br

${ }^{2}$ Universidade Estadual da Paraíba - UEPB, Campina Grande, PB, Brasil.

${ }^{3}$ Universidade Federal de Campina Grande - UFCG, Campina Grande, PB, Brasil. 
materiais na paisagem urbana quanto em função dos avanços tecnológicos que permitiram o aproveitamento e difusão de diversas rochas anteriormente não comercializada [3].

A Região Nordeste é uma das áreas mais requeridas quanto à pesquisa e exploração dessa atividade industrial, que está em grande expansão e influencia significativamente a balança comercial do Brasil. Por razões de ordem econômica, muitas pesquisas vêm sendo desenvolvidas, em vários segmentos da indústria, com a finalidade de adequar os materiais encontrados em cada região, procurando viabilizar sua extração e uso correto, proporcionando com isso, a busca de novos materiais, novos produtos e condições técnicoeconômicas que venham de encontro com as necessidades regionais dos diversos segmentos [4].

O emprego de argamassa expansiva para demolição e corte de rochas, vem sendo um dos mais procurados pelas indústrias extrativas. Os principais métodos de lavra de rochas ornamentais são as por bancadas, por painéis verticais, por desmoronamento, seletiva, de matacões e lavra subterrânea. Nesses métodos tem sido utilizada a tecnologia de argamassa expansiva, com exceção da lavra de matacões que podem usar métodos simples e conduzido através de mão-de-obra pouco especializada [5].

O emprego de argamassa expansiva para demolição e corte de rochas, vem sendo um dos mais procurados pelas indústrias extrativas, por suas inúmeras vantagens, tais como a obtenção no ganho de recuperação, pois há minimização de microfissuras no interior do maciço [3].

A argamassa expansiva funciona através de reação química que ocorre quando é misturado com uma quantidade de água ( $30 \%$ - $35 \%$ do peso do produto). Esta reação causa a dilatação da mistura, que aumenta o seu volume inicial em até quatro vezes, logo, ela age em função do próprio inchamento, exercendo nas paredes do furo uma força unitária superior a 8000 toneladas por metro quadrado, provocando o aparecimento de rachas [I].
A resistência à tração das rochas é menor que a sua resistência à compressão, variando numa faixa de $10 \%$ a $40 \%$ da segunda, de acordo com as características tecnológicas do material. A argamassa expansiva, aplicada ao longo de furos alinhados e igualmente espaçados, exerce nas paredes dos furos uma pressão de expansão, em todas as direções, agindo como um esforço compressivo. As forças dessa compressão induzem reações de tensões trativas, no plano perpendicular àquelas forças compressivas atuantes no plano dos furos, promovendo, desta maneira, a ruptura da rocha por tração [3].

A pressão de expansão varia sensivelmente com o tempo de reação e com a temperatura que se encontra a rocha. Com tempos de reação mais longos, podendo alcançar vários dias, a pressão de expansão pode chegar a valores consideravelmente superiores a 78,45 $\mathrm{MPa}\left(800 \mathrm{~kg} / \mathrm{cm}^{2}\right)$.

Para temperaturas elevadas alcançam-se determinados resultados em tempos mais breves; com temperaturas mais baixas, alcançam-se os mesmos resultados em tempos mais longos, ou resultados mais modestos para um mesmo tempo.

O tempo de reação, para geração de um corte, varia em função da temperatura ambiente, do espaçamento dos furos, das características petrológicas e mecânicas das rochas, além do seu aspecto textual e, da qualidade e tipo de argamassa a ser usada [6].

Quanto ao uso, toma-se um recipiente com capacidade suficiente, coloca-se a quantidade de água necessária e depois, lentamente, adiciona-se o pó e sempre sob agitação, fazendo-se a mistura obter uma pasta fluida, sem grumos. Coloca-se a pasta nos furos já preparados num intervalo de tempo de 5 a 15 minutos, isso pode ser observado nas Figuras la e Ib. Os furos devem ser verticais ou inclinados afim de que a pasta entre com facilidade, eles não devem ser tampados e, somente em casos de chuva, devem ser cobertos com um material impermeável evitando água nos furos; em caso de infiltração, ou onde existem
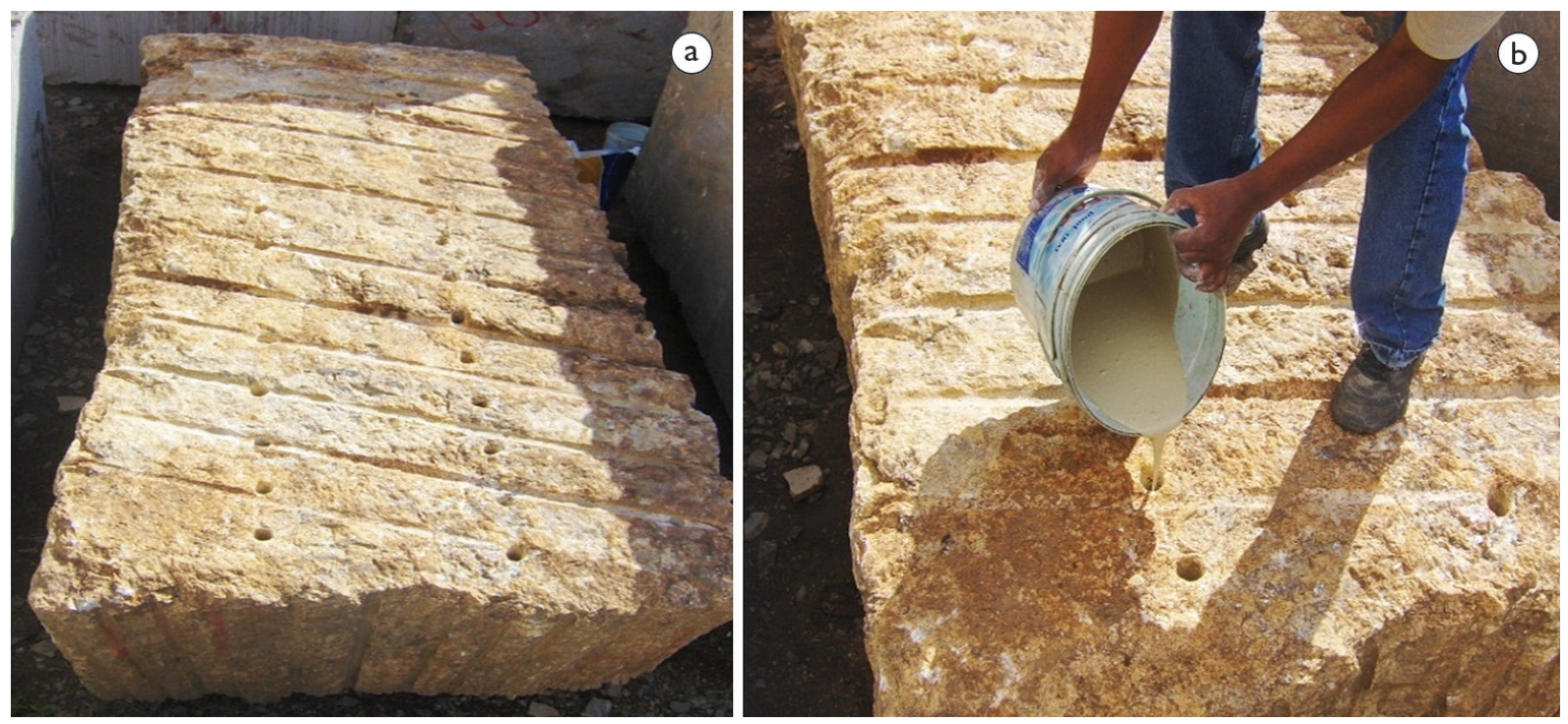

Figura I. (a) Perfurações no bloco; (b) Aplicação da argamassa no bloco [3]. 
muitas fissuras que não permitam o uso correto do furo, aconselha-se colocar dentro do furo um tubo plástico de PVC e, depois encher este último. A distância entre os furos varia em função do diâmetro dos mesmos $(32 \mathrm{~mm}$ a $50 \mathrm{~mm}$ ) e do tipo de material a ser desmontado ou cortado. O tempo de reação da argamassa hidratada depende da temperatura ambiente, trata-se de um produto alcalino de $\mathrm{pH}$ aproximadamente 13 [7].

É um produto altamente ecológico, pois além de não ser explosivo, não produz gases e nem deixa resíduos nocivos [7]. É necessária apenas a sua conservação em local seco e em recipientes invioláveis, evitando o contato com umidade e consequentemente uma expansão antecipada. Após a hidratação não deve ser colocado em recipientes estreitos ou que tenham a boca mais estreita que o fundo, como em recipientes de vidro do tipo de garrafas, frascos etc.Seu efeito expansivo resulta em corte linear, sem a necessidade de uso de explosivos, rompedores, cunhas, fios diamantados ou outros métodos de corte de rocha. A argamassa expansiva reduz o número de perfurações, aumentando assim a produção e a qualidade do produto obtido. Seu alto efeito de expansão permite cortes na vertical e horizontal, em blocos soltos, em bancadas ou em pranchas, conforme no bloco da Figura Ib [4].

Essas argamassas são preparadas pela pulverização de um clínquer obtido principalmente pela mistura de óxidos de cálcio, óxidos de silício $\left(\mathrm{SiO}_{2}\right)$ e sulfato de cálcio $\left(\mathrm{CaSO}_{4}\right)$ [7]. Entretanto, alguns autores substituíram o $\mathrm{SiO}_{2}$ pela $\mathrm{Al}_{2} \mathrm{O}_{3}$. Também estão presentes outros tipos de óxidos, como o de ferro e magnésio em menores quantidades. Deve-se calcinar o clínquer a alta temperatura, entre $1.350^{\circ} \mathrm{C}$ e $1.550^{\circ} \mathrm{C}$ [7].

Forma-se também o clínquer de uma mistura, onde destaca-se o uso de óxido de cálcio ( $80 \%$ - 95\%), cimento Portland, hidróxido de cálcio $\left(\mathrm{Ca}(\mathrm{OH})_{2}\right)$ e carbonato de cálcio $\left(\mathrm{CaCO}_{3}\right)$ [8]. Já conforme a patente de outros autores, o clínquer consiste em $\mathrm{CaO}, \mathrm{Al}_{2} \mathrm{O}_{3}$ e $\mathrm{CaSO}_{4}$, que depois de pulverizado é acrescido de cimento Portland e gesso novamente [9].

Apesar das diferenças observa-se que todas obedecem ao princípio da cinética e termodinâmica desse processo químico no qual a argamassa sofre hidratação em uma velocidade relativamente baixa, mas com aumento volumétrico e grande pressão de expansão por umidade. No controle da cinética da reação tem sido feito o uso de compostos orgânicos, das funções ácidos carboxílicos, alcoóis, com o objetivo de retardar a hidratação dos óxidos da argamassa [10].

A argamassa expansiva, para as suas devidas aplicações, deve possuir três propriedades relacionadas com a reação de hidratação, que são [I I]:

I. O início da reação deve ocorrer após um determinado tempo, ou seja, após a adição de água, devendo-se ter tempo suficiente para a colocação da mistura no furo de forma adequada ou suficiente;
2. A mistura injetada no furo deve expandir de forma que exerça pressão na estrutura a ser desmontada ou demolida de forma eficaz, sem transbordamento;

3. Durante a reação deve existir pressão expansiva suficiente para o corte da estrutura em um período de tempo relativamente curto.

O objetivo deste estudo foi desenvolver argamassas expansivas para o corte de rochas ornamentais com o auxilio da ferramenta de planejamento experimental para que assim, ocorra a otimização das composições.

\section{MATERIAIS}

Foram utilizados como materiais de pesquisa, argamassa expansiva de origem italiana, para utilizarmo-nos como parâmetro comparativo.

Para a formulação das argamassas desenvolvidas foram utilizados: calcita $\left(\mathrm{CaCO}_{3}\right)$ fornecida pela empresa Armil - Mineração do Nordeste Ltda, cimento Portland - CPII, proveniente da CIMPOR do Brasil e retardador industrial carboximetilcelulose (CMC), da LabSynth Ltda.

\section{METODOLOGIA}

Inicialmente utilizamos amostras de argamassa expansiva de origem italiana as quais foram submetidas a ensaios de caracterização, a fim de obter os parâmetros necessários para o desenvolvimento de novas formulações. Os ensaios realizados foram: análise térmica diferencial, DRX e análise granulométrica por difração de laser.

\section{I Obtenção de $\mathrm{CaO}$}

Para o desenvolvimento da argamassa expansiva foi feito um estudo com a amostra de carbonato de cálcio $\left(\mathrm{CaCO}_{3}\right)$, na forma de pó. Em seguida, essa amostra de $\mathrm{CaCO}_{3}$ foi calcinada à temperatura de $1.100^{\circ} \mathrm{C}$, com a finalidade de se obter óxido de cálcio $(\mathrm{CaO})$ que foi determinada pela seguinte reação: $\mathrm{CaCO}_{3}+$ calor $\rightarrow \mathrm{CaO}+\mathrm{CO}_{2}$ (reação endotérmica).

O $\mathrm{CaO}$ obtido a partir da queima de $\mathrm{CaCO}_{3}$ foi pulverizado e acondicionado em dessecador para evitar o contato direto com a umidade, pois o mesmo tende a hidratar podendo prejudicar o desenvolvimento da argamassa.

\subsection{Formulação das Argamassas}

Para o desenvolvimento das formulações básicas de argamassa foi elaborado um planejamento experimental no qual foram variados os seguintes componentes: $\mathrm{CaO}$ e $\mathrm{CaCO}_{3}$, possibilitando assim, que analisemos a influência de cada um deles no comportamento apresentado por cada formulação e argamassa expansiva. 
Tomando como base formulações utilizadas comumente pela indústria do setor para o desenvolvimento de argamassa expansiva foi utilizado um planejamento experimental (fatorial) do tipo $2^{2}$ com um experimento no ponto central, totalizando 5 experimentos.

Foram variadas as concentrações dos seguintes $\mathrm{CaO}$ e $\mathrm{CaCO}_{3}$ (variáveis de entrada) e a resposta analisada foi a capacidade de expansão. As formulações desenvolvidas para o estudo encontram-se na Tabela I.

A utilização do método de planejamento fatorial em estudos que abrangem muitas variáveis, como é o caso do desenvolvimento de fluidos de perfuração, é importante, pois torna possível o planejamento e a realização de maneira organizada de uma quantidade mínima necessária de experimentos, economizando tempo e recursos financeiros [12].

A regressão dos dados experimentais foi realizada utilizando o programa Statistica ${ }^{\mathrm{TM}}$ [13].

\subsection{Análise Térmica Diferencial}

A ATD determina a diferença da temperatura de uma amostra em relação a uma referência inerte, nesse caso, hidróxido de alumínio $\left(\mathrm{Al}_{2} \mathrm{O}_{3}\right)$; a medida foi feita em função da temperatura; quando ocorrem transformações endotérmicas e exotérmicas, sendo que estas aparecem como deflexões em sentidos opostos na curva termodiferencial. A ATD serviu de auxílio na interpretação da reação de hidratação exotérmica de $\mathrm{CaO}$ para $\mathrm{Ca}(\mathrm{OH})_{2}$.

Portanto, com a ATD, temos dados para explicações da cinética química e termodinâmica das reações que ocorrem na argamassa expansiva. As análises das amostras foram realizadas no Sistema de Análise Térmica modelo RB-3000-20 do Laboratório de Engenharia de Materiais - UFCG.

\subsection{Difratometria de Raios-X (DRX)}

A DRX é amplamente utilizada na caracterização das estruturas de reticulados; logo, será útil na identificação dos componentes majoritários de algumas argamassas a desenvolvidas nesse trabalho, inclusive a italiana. As medidas de difração de raios- $X$ foram realizadas em equipamento $D R X$ 6000 da Shimadzu no Laboratório de Cerâmica da UAEMa/ UFCG. A radiação utilizada foi $\mathrm{K} \alpha$ do $\mathrm{Cu}(40 \mathrm{kV} / 30 \mathrm{~mA}) \mathrm{com}$ $2 \theta$ variando de $10^{\circ}$ a $30^{\circ}$.

\subsection{Análise Química}

A análise química permitirá quantificar o teor de um determinado componente em alguma amostra, como na argamassa expansiva, como óxidos e outros compostos inorgânicos. Este ensaio foi realizado no Laboratório de Análises Minerais na UFCG.

\subsection{Granulometria a Laser}

As medidas das análises granulométricas foram determinadas em um equipamento granulômetro a laser da marca CILAS modelo I064. Este equipamento esta localizado no laboratório de Engenharia de Materiais - UFCG. As medidas da distribuição granulométrica do material foram realizadas na faixa de tamanho entre $0,5 \mu \mathrm{m}$ e $500 \mu \mathrm{m}$. Essas medidas foram realizadas em dispersões líquidas contendo material particulado em suspensão, sendo a contagem efetuada via microcomputador acoplado com interface serial. O tempo de medida total foi inferior a três minutos. Essa análise dimensional mostra-se, portanto, de extrema importância, não só na caracterização, como na análise de alguns fatores a serem abordados, como a consistência, a qual depende significativamente da granulometria.

\subsection{Teste de Avaliação de Pressão de Expansão}

Os testes que avaliaram a expansão das argamassas pelo aumento do gradiente de pressão (Teste de Avaliação de Pressão de Expansão) foram realizadas no Laboratório de Caracterização de Materiais - LMC- UFCG, no qual foi desenvolvido equipamento para avaliação de testes de pressão expansiva.

\section{RESULTADOS E DISCUSSÕES}

Inicialmente foram realizados ensaios preliminares na argamassa expansiva comercial a fim de obtermos parâmetros para em seguida desenvolvermos uma argamassa de qualidade elevada e ótima eficiência.

Os difratogramas da argamassa expansiva italiana, assim como das composições preparadas em laboratório, podem ser observados na Figura 2. Pode-se constatar a presença dos principais picos característicos do óxido de cálcio $\left(2 \theta\right.$ próximo a $\left.30^{\circ}\right)$, como fase principal, hidróxido

Tabela I. Formulações das argamassas desenvolvidas

\begin{tabular}{ccccc}
\hline Composição & $\mathbf{C a O}(\%)$ & $\mathrm{CaCO}_{3}(\%)$ & Cimento(\%) & CMC(\%)* \\
\hline AI & 70 & 10 & 10 & 4 \\
A2 & 75 & 10 & 10 & 4 \\
A3 & 70 & 15 & 10 & 4 \\
A4 & 75 & 15 & 10 & 4 \\
A5 & 60 & 25 & 10 & 4 \\
\hline
\end{tabular}

* \% em peso do total. 
de cálcio $\left(2 \theta\right.$ a cerca de $\left.18^{\circ}\right)$ e sílica $\left(2 \theta\right.$ a cerca de $\left.23^{\circ}\right)$. Há, portanto, uma correlação da argamassa tida como referência com as composições preparadas em laboratório.

Observa-se na Figura 3 a análise térmica diferencial (ATD) da argamassa expansiva italiana assim como das composições preparadas em laboratório. Pode-se observar a perda de massa referente às hidroxilas $(\mathrm{OH}-)$, entre $500^{\circ} \mathrm{C}$ e $700^{\circ} \mathrm{C}$ e de $\mathrm{CO}_{2}$ desprendido do $\mathrm{CaCO}_{3}$ durante o aquecimento, entre $700^{\circ} \mathrm{C}$ e $1.000^{\circ} \mathrm{C}$ para todas as argamassas, inclusive a italiana. Comparando-se as curvas, pode-se verificar um menor teor de $\mathrm{CaCO}_{3}$ e maior teor de $\mathrm{Ca}(\mathrm{OH})_{2}$ na argamassa comercial. Deve-se, portanto,

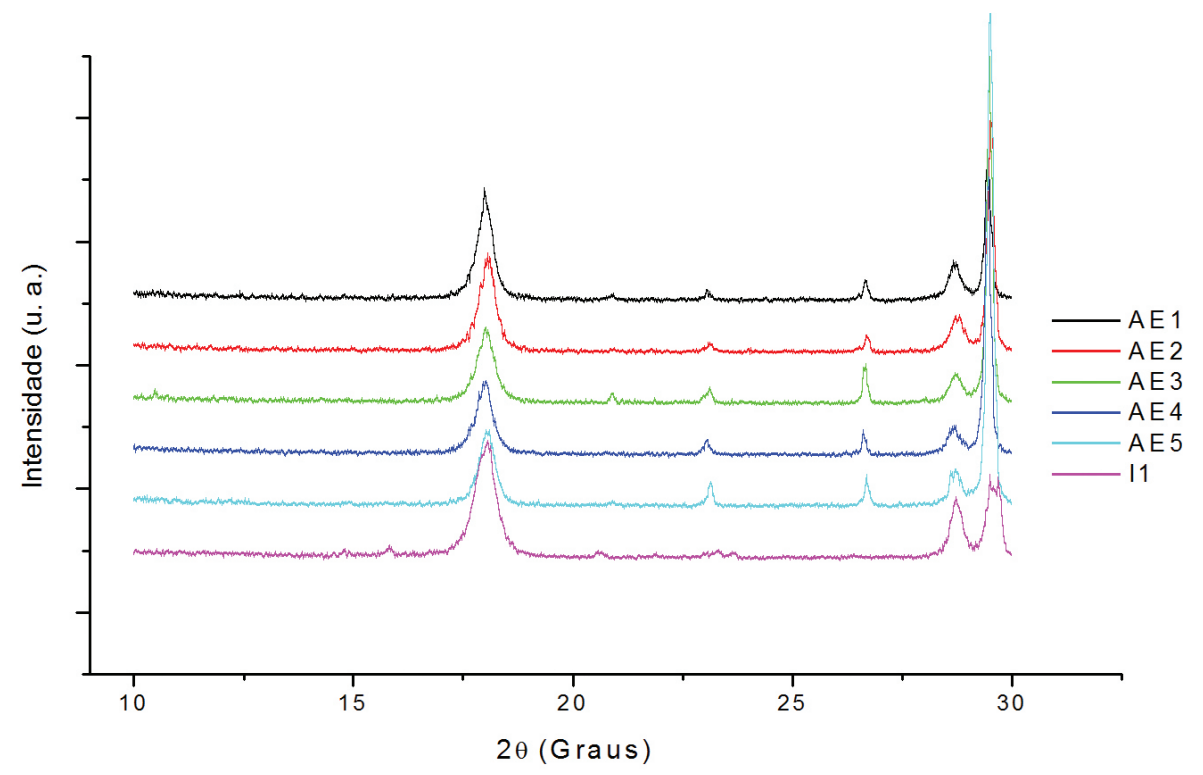

Figura 2. Análise por difração de raios- $X$ das argamassas italiana e preparadas.
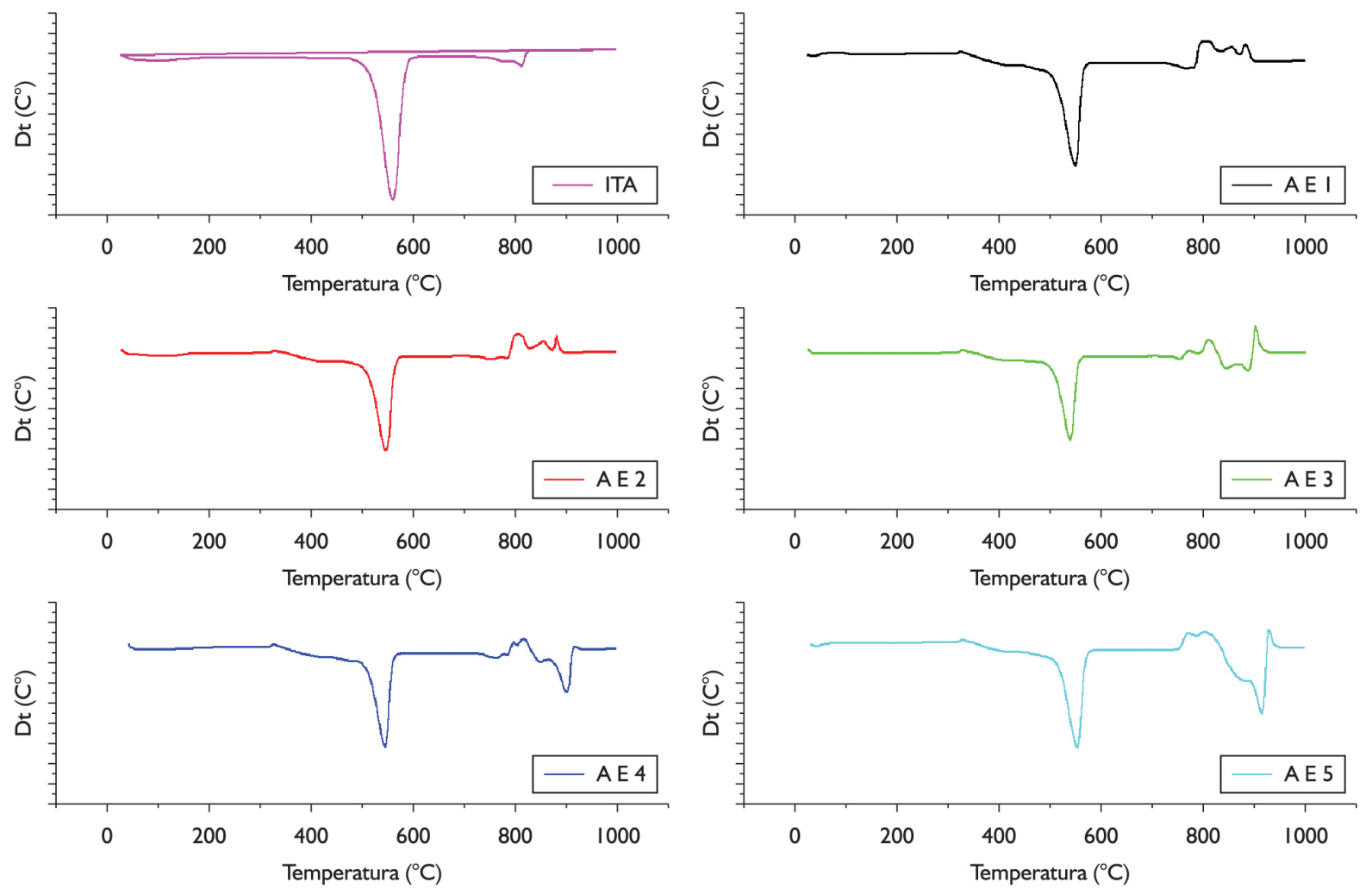

Figura 3. Análise térmica diferencial das formulações desenvolvidas. 
Tabela 2. Análise química da argamassa expansiva comercial

\begin{tabular}{lc}
\hline \multicolumn{1}{c}{ Composição } & Percentagem por peso \\
\hline $\mathrm{Pr}$ (perda ao rubro) & $25,90 \%$ \\
$\mathrm{SiO}_{2}$ (óxido de silício) & $3,76 \%$ \\
$\mathrm{Ri}_{\text {(resíduo insolúvel) }}$ & $0,44 \%$ \\
$\mathrm{Fe}_{2} \mathrm{O}_{3}$ (óxido de ferro) & $0,40 \%$ \\
$\mathrm{Al}_{2} \mathrm{O}_{3}$ (óxido de alumínio) & $T r a c ̧ o s$ \\
$\mathrm{CaO}$ (óxido de cálcio) & $63,00 \%$ \\
$\mathrm{MgO}$ (óxido de magnésio) & $3,63 \%$ \\
$\mathrm{Na}_{2} \mathrm{O}$ (óxido de sódio) & $0,90 \%$ \\
$\mathrm{~K}_{2} \mathrm{O}$ (óxido de potássio) & $1,69 \%$ \\
\hline
\end{tabular}

Tabela 3. Diâmetros médios das composições preparadas

\begin{tabular}{cc}
\hline Designação & Diâmetro médio $(\mu \mathrm{m})$ \\
\hline AI & 13,34 \\
A2 & 13,31 \\
A3 & 13,29 \\
A4 & 13,22 \\
A5 & 13,14 \\
ITA & 23,30 \\
\hline
\end{tabular}

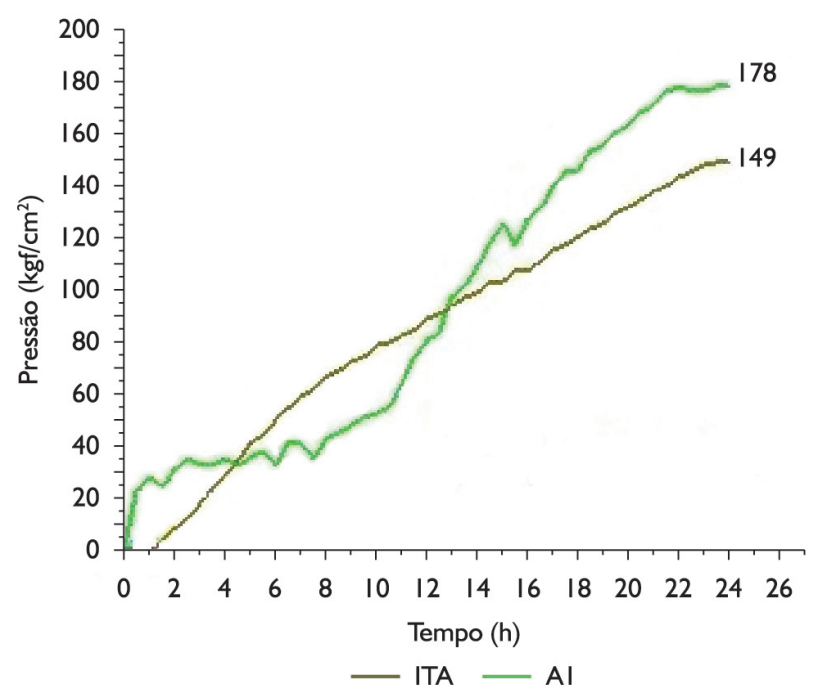

Figura 4. Teste de pressão de expansão da amostra Al preparada em laboratório e da amostra comercial italiana (ITA).

utilizar menores quantidades de $\mathrm{CaCO}_{3}$ e acrescentar quantidades suficientes de $\mathrm{CaO}$ para se ter uma melhor reprodutibilidade dos resultados.

$\mathrm{Na}$ Tabela 2 representa-se a análise química convencional feita na argamassa expansiva comercial. Por meio desta, pode-se comprovar o alto teor de óxido de cálcio, $\mathrm{CaO}$, presente; subtraindo-se a perda ao rubro $(25,9 \%)$ do $\mathrm{CaO}(63 \%)$ obtemos a porcentagem de $85 \%$, teor que indica quanto há na amostra de $\mathrm{CaO}, \mathrm{CaCO}_{3}$ e $\mathrm{Ca}(\mathrm{OH})_{2}$. Óxidos de silício e de magnésio também fazem parte de sua composição, portanto, podemos afirmar que o desenvolvimento de uma argamassa expansiva deve-se de matérias-primas de elevado teor de $\mathrm{CaO}$.

$\mathrm{Na}$ Tabela 3 estão apresentados os resultados da análise granulométrica e das composições formuladas, assim como da argamassa italiana. $O$ corte granulométrico das composições foi feito em $74 \mu \mathrm{m}$ (\#200 ABNT). Observa-se que as composições obtiveram partículas com diâmetro médio bem inferior ao da argamassa italiana que serviu de parâmetro. Esta granulometria mais fina, das argamassas preparadas, pode influenciar no tempo de reação para o aumento da pressão de expansão.

A Figura 4 mostra os resultados preliminares do teste de pressão de expansão de uma amostra preparada em laboratório e uma amostra comercial para fins de comparação de desempenho. Pode-se observar que a amostra Al obteve melhor desempenho, apresentando a pressão de expansão final de $178 \mathrm{kgf} / \mathrm{cm}^{2}$, já a amostra amplamente utilizada comercialmente apresentou desempenho inferior com pressão de expansão final de $149 \mathrm{kgf} / \mathrm{cm}^{2}$. Deste modo, pode-se indicar que a amostra da composição $\mathrm{Al}$ apresentou pressão de expansão maior que a amostra comercial, tendo a primeira apresentado uma diferença de $29 \mathrm{~kg} / \mathrm{cm}^{2}$ em relação à segunda no decorrer de 24 horas de ensaio.

Flutuações de valores durante 0 teste podem ser advindas da incorporação de ar durante o processo de moldagem da argamassa para o teste de pressão. Este tipo de problema é acentuado em argamassas que apresentam maiores viscosidades.

A massa no processo inicial de expansão, perde pressão quando encontra aberturas causadas pela formação de bolhas de ar. Outra explicação para estas flutuações pode ser ocasionado pela acomodação da argamassa durante o teste. Deste modo, um melhor controle da preparação de teste é essencial para evitar esta queda de pressão durante o processo de expansão.

\section{CONCLUSÕES}

A argamassa expansiva é formada basicamente de óxido de cálcio $(\mathrm{CaO})$, este é o responsável pela expansão via hidratação. Outros componentes também estão presentes na argamassa: $\mathrm{SiO}_{2}, \mathrm{MgO}$ e teores de $\mathrm{Fe}_{2} \mathrm{O}_{3}, \mathrm{Al}_{2} \mathrm{O}_{3}, \mathrm{Na}_{2} \mathrm{O}$ e $\mathrm{K}_{2} \mathrm{O}$.

As formulações se aproximaram das características segundo os testes analisados (ATD), apresentando os picos característicos tanto do $\mathrm{Ca}(\mathrm{OH})_{2}$ quanto do $\mathrm{CO}_{2}$ (característico do $\mathrm{CaCO}_{3}$ ). Pela análise de DRX as composições preparadas em laboratório se assemelharam das características da argamassa italiana.

As análises granulométricas de todas as formulações apresentadas tiveram valores relativamente próximos ao da argamassa comercial italiana, isso ocorreu devido a termos evitado a moagem das composições assim evitando 
desaglomeração excessiva e perda de parte do CMC, e assim, obtivemos características das partículas muito próximas ao da argamassa comercial. De acordo com o teste de pressão de expansão a argamassa desenvolvida em laboratório apresentou melhor desempenho no comparativo com a argamassa comercialmente utilizada para esta atividade.

\section{Agradecimentos}

À CAPES e ao CNPq (Processo No 305729/2010-I) pelo apoio financeiro, à System Mud Indústria e Comércio Ltda. pelo fornecimento dos aditivos estudados e ao Laboratório de Pesquisa de Fluidos de Perfuração - PEFLAB do LABDES/ UFCG.

\section{REFERÊNCIAS}

I Sebrae Minas. Setores estratégicos: rochas ornamentais 2005/2007. Belo Horizonte; 2007.

2 Cunha CTC, Lira HL, Neves GA, Sousa AAP. Estudo de matéria-prima cerâmica para obtenção de argamassa expansiva para lavra de rochas ornamentais. In: Associação Brasileira de Cerâmica. Anais do $49^{\circ}$ Congresso Brasileiro de Cerâmica; 2005 Jun. 6-9; São Pedro, Brasil. São Paulo: Associação Brasileira de Cerâmica; 2005.

3 Sousa AAP, Oliveira DF, Laranjeira E; Sousa AAP, Neves GA, Lira HL. Caracterização de argamassa expansivas comerciais para desmonte de rochas ornamentais [acesso em II set. 2009].

4 Caimex. Produtos Kayati [acesso em jan. 2008]. Disponível em: www.caimex.com.br.

5 Vidal FWH. Estudo dos elementos abrasivos de fios diamantados para a lavra de granitos do Ceará [tese de doutorado]. São Paulo: Escola Politécnica, Universidade de São Paulo; 1999.

6 Rogertec. Cimento expansivo. 2005 [acesso em jan. 2008]. Disponível em: www.rogertec.com.br.

7 Kawano T, Ishii S, inventors. Demolition agent for brittle materials. United States patent US 43I6583. 1982.

8 Moyer WW Jr, Smith-Johannsen R, inventors. Expansive cement and agent therefor. United States patent US 4205994, 1980.

9 Rice EK, inventor. Expansive cement. United States patent US 4419136, 1983.

10 Suzukawa Y, Kobayashi W, Okabayashi S, Ichinose H, inventors. Expansive cement addtive and cementitious material added therewith. United States patent US 4452637, 1984.

I I Minegishi K, Akiba T, Harada H, Takei A, Abe M, inventors. United States patent US 4409030, 1983 [acesso em dezembro de 2007]. Disponível em: www.patft.uspto.gov.

12 Barros Neto B, Scarminio IS, Bruns RE. Como fazer experimentos. Campinas: Editora Unicamp; 2003.

I 3 Statsoft Inc. Statistica for Windows, version 5.0 [CD-ROM]. São Caetano do Sul; 2000.

Recebido em: 12 Ago. 2014

Aceito em: 17 Dez. 2014 